\title{
Expanded newborn metabolic screening programme in Hong Kong: a three-year journey
}

\author{
SC Chong, LK Law, Joannie Hui, CY Lai, TY Leung, YP Yuen *
}

This article was published on 1 Sep 2017 at www.hkmj.org.

\section{A B S T R A C T}

Introduction: No universal expanded newborn screening service for inborn errors of metabolism is available in Hong Kong despite its long history in developed western countries and rapid development in neighbouring Asian countries. To increase the local awareness and preparedness, the Centre of Inborn Errors of Metabolism of the Chinese University of Hong Kong started a private inborn errors of metabolism screening programme in July 2013. This study aimed to describe the results and implementation of this screening programme.

Methods: We retrieved the demographics of the screened newborns and the screening results from July 2013 to July 2016. These data were used to calculate quality metrics such as call-back rate and false-positive rate. Clinical details of truepositive and false-negative cases and their outcomes were described. Finally, the call-back logistics for newborns with positive screening results were reviewed.

Results: During the study period, 30448 newborns referred from 13 private and public units were screened. Of the samples, $98.3 \%$ were collected within 7 days of life. The overall call-back rate was $0.128 \%$ $(39 / 30448)$ and the false-positive rate was $0.105 \%$ $(32 / 30448)$. Six neonates were confirmed to have inborn errors of metabolism, including two cases

translocase deficiency, and three milder conditions. One case of maternal carnitine uptake defect was diagnosed. All patients remained asymptomatic at their last follow-up.

Conclusion: The Centre of Inborn Errors of Metabolism has established a comprehensive expanded newborn screening programme for selected inborn errors of metabolism. It sets a standard against which the performance of other private newborn screening tests can be compared. Our experience can also serve as a reference for policymakers when they contemplate establishing a government-funded universal expanded newborn screening programme in the future.

\section{Hong Kong Med J 2017;23:489-96}

DOI: $10.12809 / \mathrm{hkmj} 176274$

\author{
1,2 SC Chong, FHKCPaed, FHKAM (Paediatrics) \\ 1,3 LK Law, PhD, FRCPath \\ 1,2 J Hui, FRCP (Edin), FRACP \\ ${ }^{4}$ CY Lai, MSc Nursing, FHKAN (Midwifery) \\ 1,4 TY Leung, MD (CUHK), FHKAM (Obstetrics and Gynaecology) \\ 1,3 YP Yuen *, FRCPath, FHKAM (Pathology) \\ ${ }^{1}$ Centre of Inborn Errors of Metabolism \\ 2 Department of Paediatrics \\ ${ }^{3}$ Department of Chemical Pathology \\ ${ }^{4}$ Department of Obstetrics and Gynaecology \\ The Chinese University of Hong Kong, Shatin, Hong Kong
} of medium-chain acyl-coenzyme A dehydrogenase deficiency, one case of carnitine-acylcarnitine

* Corresponding author: lizyuenyp@cuhk.edu.hk

New knowledge added by this study

- Running an expanded newborn screening programme in public and private hospitals in Hong Kong is feasible if sufficient clinical and logistical support can be provided.

- The incidence of inborn errors of metabolism detected by expanded newborn screening is one in 4355 births in Hong Kong. The call-back rate is $0.128 \%$.

Implications for clinical practice or policy

- Our results such as call-back rate and incidence of inborn errors of metabolism will be useful for future planning for a universal expanded newborn screening programme in Hong Kong.

- Our results illustrate that expanded newborn screening is not just a laboratory test, but also a comprehensive programme with different clinical components such as pre-test counselling and post-test timely specialised management.

\section{Introduction}

The term 'inborn errors of metabolism' (IEM) was coined by Archibald Garrod more than 100 years ago. ${ }^{1}$ Such disorder is extremely heterogeneous in clinical presentation and causes disease by either accumulation of toxic intermediary metabolites or lack of essential metabolites. In the 1960s, Robert Guthrie invented a bacterial-inhibition assay based on dried blood spots (DBS) collected on filter paper cards to detect abnormal levels of phenylalanine in patients with phenylketonuria (PKU). ${ }^{2}$ Newborn screening for PKU, other IEM, and non-IEM 
香港新生兒代謝病篩查計劃的擴展：三年的進程 莊淑貞、羅立基、許鍾妮、黎哲瑩、梁德楊、袁月冰

引言：在西方發達國家很早已經有新生兒代謝病籂查, 此等服務亦在 香港鄰近國家迅速發展。儘管如此, 香港尚未有普及的新生兒代謝病 節查計劃。為提高本地對新生兒代謝病的關注意識和做好準備, 香港 中文大學代謝病診治中心自 2013 年7月起開展了一項非資助的代謝病 篩查計劃。本研究描述這計劃的實施過程和結果

方法：我們抽查了 2013 年 7 月至 2016 年 7 月期間新生兒篩查的人口特 徵和篩查結果, 計算如回叫率和假陽性率的質量指標, 並描述了真陽 性和假陰性病例的臨床細節及結果。亦回顧了呈陽性篩選結果的新生 兒的回叫細節。

結果：研究期間由 13 個公營部門和私營機構轉介的新生兒共有 30448 人。當中 $98.3 \%$ 的樣本於嬰兒出生 7 天內收集。整體回叫率 $0.128 \%$ （39/30 448），假陽性率0.105\%（32/30 448）。有6名新生兒確診 有先天性代謝病, 包括中鏈酰基輔酶 $\mathrm{A}$ 脱氫酶缺乏症 2 例、肉樐一酰基 肉毒鹼轉位酶缺乏症 1 例, 其餘 3 例病情較輕。另有 1 例的母親確診有 肉餇缺乏症。所有患者在最後一次隨訪期間仍然維持無症狀。

結論：代謝病診治中心經已制定了一個全面的新生兒代謝病篩查計 劃, 其所定的標準可以讓其他私營的新生兒篩查測試作比較。我們的 經驗為政策制定者日後考慮施行政府資助的新生兒穊查計劃作一參 考。 public hospital in Hong Kong was conducted between July and November 2010. ${ }^{15}$ The Centre of Inborn Errors of Metabolism (CIEM) of the Chinese University of Hong Kong started a private expanded newborn metabolic screening programme in July 2013 with participants from multiple centres. This study describes the results and screening outcome of this newborn screening programme in the past 3 years.

\section{Methods}

The CIEM newborn screening programme offered opt-in screening for 34 aminoacidopathies, organic acidurias, and fatty acid oxidation disorders (Table). Daily pre-test education and counselling were done by doctors and nurses of the referring units. This process was assisted by pamphlets produced by the CIEM. ${ }^{16}$ Parents were asked to sign a consent form after the education and counselling session. Referring hospitals were instructed to perform a heel prick for newborn babies between 24 hours and 7 days after birth and spot a few drops of blood onto a filter paper card provided by the CIEM. Apart from basic demographic information such as date and time of birth, the date and time of the DBS collection, ethnicity, feeding methods, medications, and family history of IEM were also collected. The screening laboratory ran the MS/MS assay for IEM screening daily from Monday to Friday. Eleven amino acids, succinylacetone, free carnitine, and 30 acylcarnitines were analysed by the Neobase non-derivatized MSMS kit (PerkinElmer, Waltham [MS], US) on a Quattro Micro tandem quadrupole mass spectrometer (Waters, Milford [MS], US). In the initial phase, laboratory cut-offs at 1 and 99 percentiles for these 43 analytes were calculated using results from 200 healthy newborns. These cutoffs were then updated regularly as more normal data were accumulated. We also compared our cut-offs with the clinically validated cut-offs in the Region 4 Stork (R4S) MS/MS project. The R4S MS/MS project is a web-based application for laboratory quality improvement of newborn screening by MS/MS. ${ }^{17}$ Screen-positive results were classified as 'uncertain' if the abnormal analyte(s) was only mildly elevated or 'positive' if the abnormal analyte(s) was markedly elevated or the abnormal analyte pattern was highly suggestive of a specific IEM. Post-analytical tools in the R4S MS/MS project (https://clir.mayo.edu/) were also used to assist result interpretation. ${ }^{18}$ The final screening reports were authorised by a trained chemical pathologist and a professionally qualified scientist. The clinical team, which consisted of metabolic paediatricians and newborn screening nurses, was notified immediately for any positive screening result. For each neonate with a positive screen, a second DBS card was collected. Additional blood and urine were usually collected at the same 
TABLE. Target IEM of the CIEM newborn screening programme

\begin{tabular}{|c|c|}
\hline IEM categories & Target IEM \\
\hline \multirow[t]{9}{*}{ Amino acid disorders } & Phenylketonuria \\
\hline & Maple syrup urine disease \\
\hline & Citrullinaemia type 1 \\
\hline & Argininosuccinic aciduria \\
\hline & Homocystinuria \\
\hline & Tyrosinaemia type 1 \\
\hline & Arginase deficiency \\
\hline & Defects of biopterin cofactor biosynthesis and regeneration citrullinaemia type 2 \\
\hline & Hypermethioninaemia \\
\hline \multirow[t]{14}{*}{ Organic acid disorders } & Propionic aciduria \\
\hline & Methylmalonic aciduria (MUT, cblA, cblB) \\
\hline & Isovaleric aciduria \\
\hline & Beta-ketothiolase deficiency \\
\hline & Glutaric aciduria type 1 \\
\hline & 3-Hydroxy-3-methylglutaryl-CoA lyase deficiency \\
\hline & Multiple carboxylase deficiency \\
\hline & 3-Methylcrotonyl-CoA carboxylase deficiency \\
\hline & 2-Methyl-3-hydroxybutyric aciduria* \\
\hline & Malonic aciduria \\
\hline & 3-Methylglutaconic aciduria type I \\
\hline & Isobutyryl-CoA dehydrogenase deficiency ${ }^{*}$ \\
\hline & 2-Methylbutyryl-CoA dehydrogenase deficiency* \\
\hline & $\mathrm{cbl} \mathrm{C}$ and $\mathrm{cbl} \mathrm{D}$ \\
\hline \multirow[t]{11}{*}{ Fatty acid oxidation disorders } & Carnitine uptake defect \\
\hline & Medium-chain acyl-CoA dehydrogenase deficiency \\
\hline & Very long-chain acyl-CoA dehydrogenase deficiency \\
\hline & Long-chain hydroxyacyl-CoA dehydrogenase deficiency \\
\hline & Trifunctional protein deficiency \\
\hline & Short-chain acyl-CoA dehydrogenase deficiency ${ }^{\star}$ \\
\hline & Carnitine palmitoyltransferase I deficiency \\
\hline & Carnitine palmitoyltransferase II deficiency \\
\hline & Carnitine-acylcarnitine translocase deficiency \\
\hline & Multiple acyl-CoA dehydrogenase deficiency \\
\hline & Medium- / short-chain hydroxyacyl-CoA dehydrogenase deficiency \\
\hline
\end{tabular}

Abbreviations: $\mathrm{cbl}=$ cobalamin; $\mathrm{CIEM}=$ Centre of Inborn Errors of Metabolism; CoA = coenzyme A; IEM = inborn errors of metabolism

* Removed from the target panel since February 2016

time for confirmatory metabolic investigations (eg the knowledge of general practitioners, nurses, and plasma amino acid and urine organic acid analysis). laboratory staff on newborn screening. Continuous The exact course of action was determined on a support was also provided to all the referring doctors case-by-case basis. The workflow and logistics and hospitals, especially on proper collection of DBS arrangement of the CIEM screening programme are and interpretation of abnormal screening results. summarised in the Figure.

The CIEM also organises on-going yearly training to

Before and soon after launching of the CIEM midwives about newborn screening. newborn screening programme, a series of seminars and briefing sessions were organised in order to boost

Data for the CIEM newborn screening programme between July 2013 and July 2016 were 


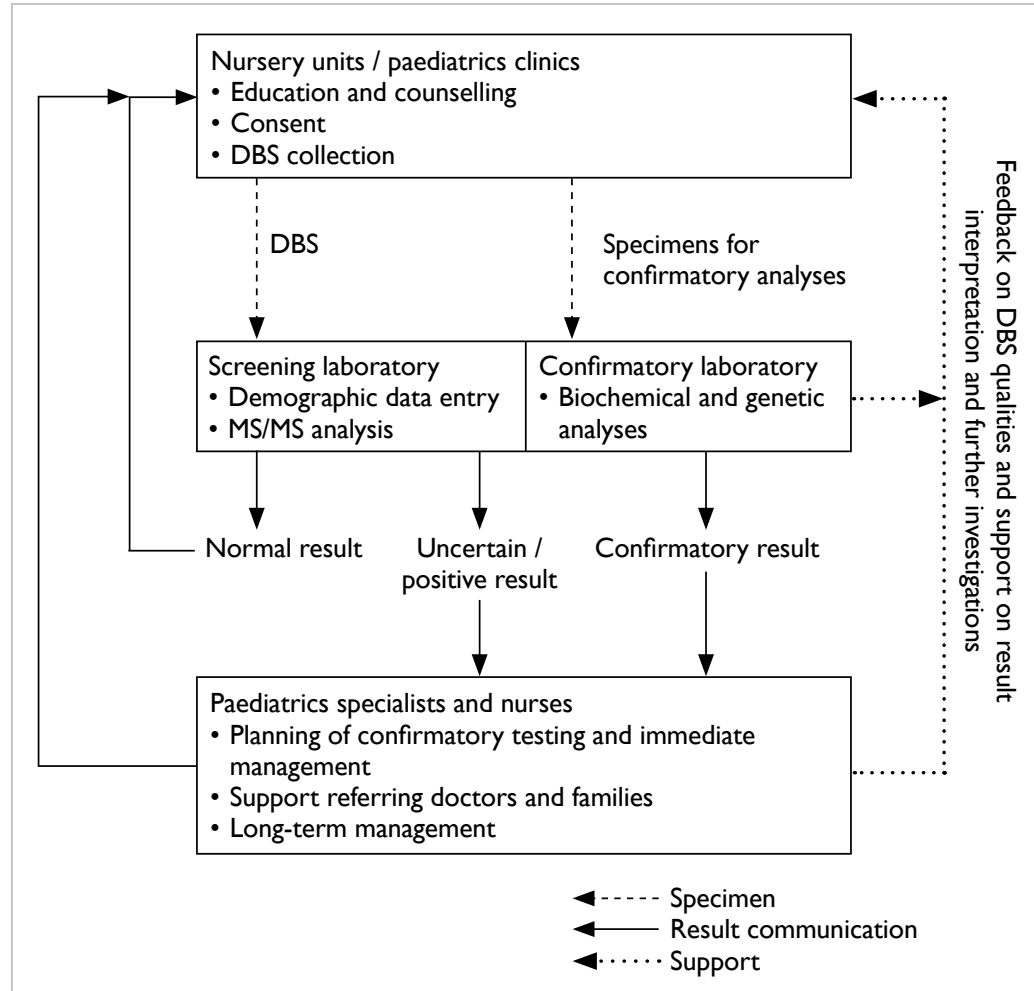

FIG. Workflow and logistics arrangement of the expanded newborn screening programme run by the Centre of Inborn Errors of Metabolism

Abbreviations: DBS = dried blood spots; $\mathrm{MS} / \mathrm{MS}$ = tandem mass spectrometry retrieved. Basic demographics of the screened newborns, collection details for the DBS cards, call-back rate, false-positive rate, clinical details and outcomes of the true-positive cases, and callback logistics were reviewed. This study was done in accordance with the principles outlined in the Declaration of Helsinki.

\section{Results}

From July 2013 to July 2016, a total of 30488 local newborn babies were screened. The total number of births during the same period was estimated to be $186216 .{ }^{19}$ Therefore, approximately $16 \%$ of all newborns born between July 2013 and July 2016 were screened. The CIEM received DBS cards from the nursery units of nine of 10 private and two of eight public hospitals, and two paediatrics clinics in Hong Kong. Over 95\% of the screened babies were Chinese and $2.7 \%$ were Caucasians. More than 98.3\% of the DBS cards were collected within 7 days of life. Approximately $81 \%$ of the screening results were available in 2 calendar days and over $98 \%$ were available in 4 calendar days. Further analysis showed that most DBS cards with a turnaround time longer than 4 calendar days were received just before long holidays (eg the Lunar New Year holiday in 2014 and 2015). This is a well-known potential pitfall of a newborn screening programme, as most screening laboratories do not operate 7 days a week. In view of this, the CIEM added two extra half-day services during the Lunar New Year holiday in February 2016 to reduce the chance of delayed diagnosis.

Thirty-nine neonates had positive screening results (four 'positive' and 35 'uncertain') and were called back for repeated DBS with or without additional metabolic investigations. The call-back rate was $0.128 \%(39 / 30448)$. Six neonates (patients 1 to 6) were subsequently confirmed to have IEM by biochemical and molecular genetic testing. One neonate (patient 7) was confirmed to have abnormal newborn screening results due to a defect in maternal carnitine uptake. Details of patients 1 to 7 are described below. The false-positive rate was $0.105 \%$ (32/30 448). Among the 32 false-positive results, 17 had low free carnitine concentrations (range, 3.8-8.0 $\mu \mathrm{mol} / \mathrm{L}$ ) with or without low longchain acylcarnitines, which constituted the most common cause of false-positive results.

\section{Patients 1 and 2}

Two siblings from the same Caucasian family were confirmed to have medium-chain acyl-coenzyme A dehydrogenase (MCAD) deficiency. Patient 1 was a full-term baby girl born by vaginal delivery. The first DBS sample showed marked elevations of C8carnitine at $7.49 \mu \mathrm{mol} / \mathrm{L}$ (cut-off, $<0.22 \mu \mathrm{mol} / \mathrm{L}$ ) and other medium-chain acylcarnitines. The diagnosis of MCAD deficiency was confirmed by mutation analysis of the $A C A D M$ gene. The parents were counselled to feed their baby regularly and avoid fasting. Patient 1 was almost 3 years old at the time of the study and remained clinically asymptomatic. Patient 2 was the younger sister of patient 1 . Her C8-carnitine concentration in the first DBS card collected before 48 hours after birth was 15.2 $\mu \mathrm{mol} / \mathrm{L}$. She shared the same $A C A D M$ genotype as patient 1 and also remained clinically well, and did not require active treatment.

\section{Patient 3}

Patient 3 was a boy with carnitine-acylcarnitine translocase (CACT) deficiency. He was born at 36 weeks and 2 days with a birth weight of $2.26 \mathrm{~kg}$. The first DBS card was collected at 31 hours of life. He developed hypothermia, hypoglycaemia, hyperammonaemia, and bradycardia requiring active resuscitation with mechanical intubation at 42 hours of life. The newborn screening result was available at 50 hours of life and showed elevated C16-carnitine and C18:1-carnitine at $12.02 \mu \mathrm{mol} / \mathrm{L}$ (cut-off, $<6.66 \mu \mathrm{mol} / \mathrm{L}$ ) and $6.32 \mu \mathrm{mol} / \mathrm{L}$ (cut-off, $<3.30 \mu \mathrm{mol} / \mathrm{L}$ ), respectively. This acylcarnitine pattern was highly suggestive of CACT deficiency or carnitine palmitoyltransferase II deficiency. Follow-up genetic testing confirmed the diagnosis of CACT deficiency. Such deficiency is notorious 
for its early presentation in the postnatal period, with a high neonatal mortality rate. ${ }^{20,21}$ Although the newborn screening result was only available after patient 3 became symptomatic, early availability of the screening result has greatly assisted the neonatologists and metabolic paediatricians by guiding the direction of clinical management. With appropriate dietary and other management, the clinical condition of the patient remained good and he had normal neurodevelopment at 1.5 years of age.

\section{Patient 4}

Patient 4 was a girl with hyperphenylalaninaemia. She was born at 40 weeks of gestation with a birth weight of $3.45 \mathrm{~kg}$. The first and second DBS showed elevated phenylalanine at $152 \mu \mathrm{mol} / \mathrm{L}$ and $89 \mu \mathrm{mol} / \mathrm{L}$ (cut-off, $<88 \mu \mathrm{mol} / \mathrm{L}$ ), respectively. Her urinary pterins were normal. Her plasma phenylalanine levels were monitored for 2 years, and ranged from 210 to $434 \mu \mathrm{mol} / \mathrm{L}$ while the patient was receiving an unrestricted diet. Genetic testing by sequence analysis and multiplex ligation-dependent probe amplification only detected a single mutation in the $P A H$ gene. The patient received no specific dietary management and she had normal neurodevelopment up to the age of 2 years.

\section{Patient 5}

Patient 5 was a full-term boy with elevated C5carnitine at $0.52 \mu \mathrm{mol} / \mathrm{L}$ (cut-off, $<0.48 \mu \mathrm{mol} / \mathrm{L}$ ) in his first newborn screen. Repeated DBS showed persistent elevation of C5-carnitine at 0.68 $\mu \mathrm{mol} / \mathrm{L}$. Urinary organic acid analysis showed elevated 2-methylbutylglycine. This result was highly suggestive of 2-methylbutyrylglycinuria (2-MBG) and excluded the more severe organic acid disorder isovaleric aciduria (IVA), which shared the same acylcarnitine marker as 2-MBG in newborn screening. The diagnosis was subsequently confirmed by genetic analysis of the $A C A D S B$ gene. 2-Methylbutylglycinuria is a relatively benign IEM and the patient had normal development at the age of 2 years without any specific treatment.

\section{Patient 6}

Patient 6 was a full-term girl whose first and second DBS showed elevated methionine at $138 \mu \mathrm{mol} / \mathrm{L}$ and $309 \mu \mathrm{mol} / \mathrm{L}$ (cut-off, $<39 \mu \mathrm{mol} / \mathrm{L}$ ), respectively. Following exclusion of homocystinuria, she was diagnosed with methionine adenosyltransferase deficiency by genetic testing. The patient was asymptomatic during the first year of life and was followed up at a metabolic clinic.

\section{Incidental finding: maternal metabolic disorder}

A mother with carnitine uptake defect (CUD) was diagnosed incidentally through the abnormal newborn screening result for her baby. The baby of this CUD patient had a low free carnitine level (2.1 $\mu \mathrm{mol} / \mathrm{L}$; cut-off, $>6.4 \mu \mathrm{mol} / \mathrm{L}$ ) in the first DBS sample, which returned to normal on subsequent monitoring without the need for carnitine supplementation. Analysis of the mother showed that her serum free carnitine level was $1.08 \mu \mathrm{mol} / \mathrm{L}$ only. Maternal CUD causing low free carnitine in newborn screening was suspected. This was later confirmed by genetic analysis of the $S L C 22 A 5$ gene. The mother had good past health throughout her life and during the pregnancy period. Her cardiac function was normal at the time of diagnosis. She was subsequently referred to a cardiologist for follow-up and was given carnitine supplementation therapy.

\section{False-negative case}

The CIEM screening programme did not have a mechanism to track false-negative results. Still one false-negative result was identified. The patient was a full-term baby girl with a body weight of $2.5 \mathrm{~kg}$. She had newborn screening done on day 3 of life and the result was normal. In particular, her citrulline level was $19 \mu \mathrm{mol} / \mathrm{L}$ (cut-off, $<30 \mu \mathrm{mol} / \mathrm{L}$ ). She presented with prolonged jaundice at 1 month of age and was found to have a raised plasma citrulline level at $497 \mu \mathrm{mol} / \mathrm{L}$ (reference range, 3-35 $\mu \mathrm{mol} / \mathrm{L}$ ). Citrin deficiency was later confirmed by genetic analysis of the SLC25A13 gene.

\section{Call-back logistics}

This programme involved the participation of maternity units of 11 hospitals, including two public and nine private hospitals, and two paediatrics clinics. All 39 babies with positive screening results were successfully called back within an appropriate time-frame for follow-up investigations. Some of the call-backs were done by the referring doctors at their private clinics or hospitals while some were arranged by and done at the CIEM. Our experience showed that with proper education and professional support, the referring paediatricians were able to handle the call-backs of borderline abnormal results (eg free carnitine slightly below the cut-off) at the referring site and liaise with the CIEM for followup investigations. This practice not only lowered the workload of our metabolic paediatricians and newborn screening nurses, but also increased engagement of community paediatricians. For abnormal results requiring urgent clinical attention, the families were informed directly by our metabolic paediatricians, who would arrange urgent admission.

\section{Discussion}

Expanded newborn screening for IEM by MS/MS has been widely adopted by many countries in the 
world for many years. Through early diagnosis and treatment, acute metabolic decompensations and long-term morbidity and mortality of many IEM can be prevented. In Hong Kong, medical practitioners and the general public are familiar with the cord blood screening programme for G6PD deficiency and congenital hypothyroidism, which is a very successful screening programme with highly satisfactory population coverage and outcome. However, little attention has been paid to IEM screening until recently. ${ }^{15}$ The Department of Health and Hospital Authority have done a pilot study on newborn screening for IEM in two public hospitals since October 2015. The establishment of the CIEM and its expanded newborn screening programme in 2013 has made this kind of screening service more readily accessible to local parents who understand the significance of IEM and opt for a private screening service for their newborn babies. The CIEM has successfully established a comprehensive screening programme, which comprises education, counselling, DBS collection, MS/MS screening, reporting, call-back, confirmatory investigations, and long-term follow-up and treatment. The CIEM screening programme quickly gained acceptance from private and public medical practitioners and now receives DBS cards from 11 hospital nursery units and two paediatrics clinics.

From July 2013 to July 2016, a total of 39 newborn babies were called back for abnormal screening results. Our experience showed that parental acceptance of abnormal screening results was generally good and this was likely the result of proper education and counselling before DBS collection. During the same period, we confirmed six cases of IEM through newborn screening and one false-negative case was identified. The incidence of IEM detected by this screening programme was one in 4355 . The figure is very similar to that from previous local studies and other IEM prevalence studies in the Chinese population. ${ }^{11,12,22,23}$

Patient 3, with CACT deficiency, presented with hypoglycaemia and bradycardia before the newborn screening result was available. This is not unexpected because CACT deficiency is notorious for its early neonatal onset and high mortality rate. ${ }^{20,21}$ For this particular case, although newborn screening did not prevent the development of life-threatening clinical symptoms, it did provide an early diagnosis, which was extremely useful to the paediatricians. This case also illustrates that screening laboratories operating on a 5-day week may not be sufficient to meet the clinical needs and may delay the diagnosis of neonates born before or during weekends or long holidays. Operating a screening laboratory on a 7-day week, however, will increase the cost of the screening programme. A balance between the two is necessary.
By screening the abnormal analytes for important IEM, some less clinically important IEM may be revealed. For example, patient 5 had elevated C5-carnitine, which has two main differential diagnosis, one is IVA and the other is 2 -MBG. Of note, IVA is an important organic acid disorder. Affected patients usually present with hyperammonaemia, metabolic acidosis, and acute metabolic decompensation. On the other hand, 2-MBG is a disorder of uncertain clinical significance. Although the exact clinical course is not yet clear, there is no case report demonstrating a definite clinical correlation between 2-MBG and any long-term mortality and morbidity. After conducting a review in February 2016, the CIEM decided to remove $2-\mathrm{MBG}$ from the list of target IEM. This can minimise the potential harm of labelling an otherwise healthy neonate with a life-long label of an IEM of uncertain clinical significance that does not require any treatment.

Until a government-funded universal expanded newborn screening service is available in Hong Kong, private medical practitioners are charged with the task of selecting newborn screening service providers for their clients. Some medical practitioners may focus on the number of screening targets when they choose a screening service provider and mistakenly believe the more the better. Nonetheless, we should not ignore the harm (eg the anxiety generated by a false-positive result) of over-screening. Other than the appropriateness of the screening targets, the turnaround time of the screening tests and the availability of confirmatory investigations are also crucial. Many screening targets may present in the early neonatal period. For a screening test to exert its maximum benefits, the results should be available within a reasonable time-frame. No newborn screening tests are confirmatory by themselves. Therefore, whenever there is a positive newborn screening result, further investigations to confirm or refute the diagnosis must be in place. Medical practitioners who use a private newborn screening service must be aware of this point and ensure all further investigations generated by a positive newborn screening result are acceptable and affordable by their patients. The use of spot urinary specimens instead of DBS for newborn screening is appealing to parents as collection of urine does not require a heel prick and thus appears to be non-invasive. Parents should be educated that heel prick using standard devices and done by well-trained nurses or phlebotomists are non-traumatic and generate no harm to newborn babies. They should also be made aware that DBS is the standard sample of choice adopted by most, if not all, national newborn screening programmes.

The scale and duration of this study is far from sufficient to draw any conclusion on financial benefits 
or cost-effectiveness of expanded newborn screening. From a public service perspective, a condition is appropriate for screening if early diagnosis has demonstrated benefits and is cost-effective. Both local and international studies have shown the cost-efficiencies gained by adopting MS/MS technology for expanded newborn screening. ${ }^{24-26}$ The available evidence is sufficient for policymakers to consider implementing a universal expanded screening programme in Hong Kong.

\section{Conclusion}

The CIEM has established a comprehensive expanded newborn screening programme for selected IEM. The programme involves pre-test counselling, a good logistics arrangement for efficient incoming referral and reporting, a readily available confirmatory testing service and, most importantly, timely management by medical and nursing specialists. Each component contributes towards a successful newborn screening programme. This screening programme not only increases the awareness of local health care workers and the general public of newborn screening, but also sets a standard against which the performance of other private newborn screening tests can be compared. In the Hong Kong SAR Chief Executive's Policy Address 2017, it was announced that the government plans to extend its pilot newborn screening service from two to all public hospitals with maternity wards in phases from the second half of 2017-18. ${ }^{27}$ Our experience could serve as a reference for policymakers when they contemplate establishing a government-funded universal expanded newborn screening programme in the future.

\section{Acknowledgement}

The CIEM would like to express sincere gratitude to the Joshua Hellmann Foundation for Orphan Diseases for their generous donation and continuous support. The Foundation had no role in the design of the study; collection, analysis, or interpretation of the data; writing, review, or approval of the manuscript; or the decision to submit the manuscript for publication.

\section{Declaration}

The authors have disclosed no conflicts of interest.

\section{References}

1. Garrod AE. The incidence of alkaptonuria: a study in chemical individuality. Lancet 1902;160:1616-20.

2. Guthrie R, Susi A. A simple phenylalanine method for detecting phenylketonuria in large populations of newborn infants. Pediatrics 1963;32:338-43.

3. Millington DS, Norwood DL, Kodo N, Roe CR, Inoue F. Application of fast atom bombardment with tandem mass spectrometry and liquid chromatography/mass spectrometry to the analysis of acylcarnitines in human urine, blood, and tissue. Anal Biochem 1989;180:331-9.

4. Chace DH, Millington DS, Terada N, Kahler SG, Roe CR, Hofman LF. Rapid diagnosis of phenylketonuria by quantitative analysis for phenylalanine and tyrosine in neonatal blood spots by tandem mass spectrometry. Clin Chem 1993;39:66-71.

5. Boyle CA, Bocchini JA Jr, Kelly J. Reflections on 50 years of newborn screening. Pediatrics 2014;133:961-3.

6. Therrell BL, Padilla CD, Loeber JG, et al. Current status of newborn screening worldwide: 2015. Semin Perinatol 2015;39:171-87.

7. American College of Medical Genetics Newborn Screening Expert Group. Newborn screening: toward a uniform screening panel and system-executive summary. Pediatrics 2006;117(5 Pt 2):S296-307.

8. Advisory Committee on Heritable Disorders in Newborns and Children. Recommended uniform screening panel. Available from: https://www.hrsa.gov/ advisorycommittees/mchbadvisory/heritabledisorders/ recommendedpanel/. Accessed 17 Jan 2017.

9. Padilla CD, Therrell BL. Newborn screening in the Asia Pacific region. J Inherit Metab Dis 2007;30:490-506.

10. Tada K, Tateda H, Arashima S, et al. Follow-up study of a nation-wide neonatal metabolic screening program in Japan. A collaborative study group of neonatal screening for inborn errors of metabolism in Japan. Eur J Pediatr 1984;142:204-7.

11. Niu DM, Chien YH, Chiang CC, et al. Nationwide survey of extended newborn screening by tandem mass spectrometry in Taiwan. J Inherit Metab Dis 2010;33(Suppl 2):S295-305.

12. Gu X, Wang Z, Ye J, Han L, Qiu W. Newborn screening in China: phenylketonuria, congenital hypothyroidism and expanded screening. Ann Acad Med Singapore 2008;37(12 Suppl):107-4.

13. Lim JS, Tan ES, John CM, et al. Inborn Error of Metabolism (IEM) screening in Singapore by electrospray ionizationtandem mass spectrometry (ESI/MS/MS): An 8 year journey from pilot to current program. Mol Genet Metabo 2014;113:53-61.

14. Lam ST, Cheng ML. Neonatal screening in Hong Kong and Macau. Southeast Asian J Trop Med Public Health 2003;34 Suppl 3:73-5.

15. Mak CM, Lam C, Siu W, et al. OPathPaed service model for expanded newborn screening in Hong Kong SAR, China. Br J Biomed Sci 2013;70:84-8.

16. Joshua Hellmann Foundation-Newborn metabolic screening program. Available from: http://www.obg.cuhk. edu.hk/fetal-medicine/fetal-medicine_services/iem/. Accessed Jan 2017.

17. McHugh D, Cameron CA, Abdenur JE, et al. Clinical validation of cutoff target ranges in newborn screening of metabolic disorders by tandem mass spectrometry: a worldwide collaborative project. Genet Med 2011;13:23054.

18. Hall PL, Marquardt G, McHugh DM, et al. Postanalytical tools improve performance of newborn screening by tandem mass spectrometry. Genet Med 2014;16:889-95.

19. Population Estimates. Census and Statistical Department, The Hong Kong SAR Government. Available from: https:// www.censtatd.gov.hk/hkstat/sub/sp150.jsp?tableID=004\& 
ID=0\&productType $=8$. Accessed 28 Jun 2017.

20. Vitoria I, Martín-Hernández E, Peña-Quintana L, et al. Carnitine-acylcarnitine translocase deficiency: experience with four cases in Spain and review of the literature. JIMD Rep 2015;20:11-20.

21. Lee RS, Lam CW, Lai CK, et al. Carnitine-acylcarnitine translocase deficiency in three neonates presenting with rapid deterioration and cardiac arrest. Hong Kong Med J 2007;13:66-8.

22. Lee HC, Mak CM, Lam CW, et al. Analysis of inborn errors of metabolism: disease spectrum for expanded newborn screening in Hong Kong. Chin Med J (Engl) 2011;124:9839.

23. Hui J, Tang NL, Li CK, et al. Inherited metabolic diseases in the Southern Chinese population: spectrum of diseases and estimated incidence from recurrent mutations.
Pathology 2014;46:375-82.

24. Cipriano LE, Rupar CA, Zaric GS. The cost-effectiveness of expanding newborn screening for up to 21 inherited metabolic disorders using tandem mass spectrometry: results from a decision-analytic model. Value Health 2007;10:83-97.

25. Ng VH, Mak CM, Johnston JM. Cost-effectiveness analysis of newborn screening for organic acidemias in Hong Kong. SM J Clin Pathol 2016;1:1001.

26. Grosse SD, Thompson JD, Ding Y, Glass M. The use of economic evaluation to inform newborn screening policy decisions: the Washington State experience. Milbank Q 2016;94:366-91.

27. The 2017 Policy Address. Available from: https://www. policyaddress.gov.hk/2017/eng/pdf/PA2017.pdf. Accessed Aug 2017. 